Research Article

\title{
Reliability Assessment of Steel-Concrete Composite Beams considering Metal Corrosion Effects
}

\author{
Trong-Ha Nguyen (iD) and Duy-Duan Nguyen (iD \\ Department of Civil Engineering, Vinh University, Vinh 461010, Vietnam \\ Correspondence should be addressed to Duy-Duan Nguyen; duan468@gmail.com
}

Received 24 September 2020; Revised 16 November 2020; Accepted 28 November 2020; Published 9 December 2020

Academic Editor: Raffaele Landolfo

Copyright (c) 2020 Trong-Ha Nguyen and Duy-Duan Nguyen. This is an open access article distributed under the Creative Commons Attribution License, which permits unrestricted use, distribution, and reproduction in any medium, provided the original work is properly cited.

\begin{abstract}
Steel-concrete composite (SCC) beams have been widely used in civil engineering and industrial structures. This kind of structure has some advantages such as fast fabrication time and optimized weight. However, designers are often concerned about the initial reliability, while over time the structural reliability will be reduced, especially due to metal corrosion. The objective of the paper is to assess the structural reliability of corroded SCC beams, in which the input parameters are considered as random variables. The SCC beam has been designed according to Eurocode-4 (EC-4), in which input parameters consist of cross-sectional dimensions of the beam, material properties, and applied loads. The effects of the random input variables on the reliability of structures are evaluated by sensitivity analyses, which are calculated by the global sensitivity analysis using Sobol's method and Monte Carlo simulation. The developed reliability analysis algorithm in this study is verified with previous studies, highlighting the capability of the used method. Four different corrosion levels, which are pristine, 10-year, 20-year, and 50-year, are considered in the sensitivity analyses of the SCC beam. Finally, a series of first-order and total-order Sobol's indices are obtained for measuring the sensitivity of input parameters with four corrosion levels.
\end{abstract}

\section{Introduction}

The metal corrosion phenomenon has great harm to infrastructures, especially steel structures. Metal corrosions have not only decreased the structural capacity and safety but also raised the expensive cost for maintenance and replacement $[1,2]$. Therefore, studies on the assessment of deterioration capacity and reliability of structures due to corrosion effects are extremely necessary. The reliability of a structure is defined as the failure probability of a structural component [3], expressed by

$$
P_{f}=\int_{g(X) \leq 0} f x(X) \mathrm{d} x
$$

where $X=\left\{X_{i}\right\}$ is the vector of the input random variables; $g(X)$ is the limit state function of the stochastic model; $f_{X}(X)$ is the joint probability density function of vector $X$. The safe region is defined by $g(X)<0$, inversely the failure region is defined by $g(X)>0$, and the failure surface is defined by $g(X)=0$.

The service life of structures is also gradually reduced due to the degradation of the strength of structural members. Numerous studies evaluated the life-cycle and life-time performances of reinforced concrete [4-6] and steel structures [7-10]. They emphasized that it is necessary to assess the structural capacity and reliability with time.

The reliability assessment is an interesting topic for researchers. Kiureghian et al. [11] assessed the reliability of the steel frame under the dynamic loads generated from the $1940 \mathrm{El}$ Centro earthquake using $\beta$ distribution method. This approach was also used in Hong et al. [12] to study the reliability of steel frames according to the plastic limit state. Hadianfard and Razani [13] applied the Monte Carlo simulation method to investigate the reliability of steel frames with a flexible beam-column joint. The rotational stiffness and the moment-resisting of the connection were referred to in Chen et al. [14]. Aleksander [15] proposed a flexible joint 
model based on empirical tests and Eurocode- 3 to perform reliability analyses.

Reliability assessments of steel beams and SCC beams have been conducted numerously. Zhao et al. [16] performed the fatigue-reliability evaluation of steel bridges according to the American association of state highway and transportation officials (AASHTO) guidelines. Galambos et al. [17] used the first-order reliability method (FORM) for assessing the reliability of the structural member stability criteria in the 2005 AISC specification. Mamuda et al. [18] implemented the reliability assessment of SCC beams according to EC-4 using FORM. Recently, some studies on the reliability of steel beams and reinforced concrete beams have been published [19-23]. However, a consideration of the influence of metal corrosion on structural reliability is required.

There are many studies, which investigated the effects of metal corrosion on the reliability of structures. The reliability of steel structures under the corrosion was considered by Melchers [24]. Kayser and Nowak [25] developed a damage model, which was used for evaluating the reliability of corroded steel girder bridges. Landolfor et al. [26] presented a damage model induced by atmospheric corrosion for metal structures. Likewise, Czarnecki and Nowak [27] proposed time-variant reliability models for steel girder bridges. Fontaine et al. [28] investigated the influence of corrosion on the reliability of steel offshore structures. However, previous studies mostly focused on the structural reliability and sensitivity of steel and SCC structures. A study on the investigation of the effects of metal corrosion on the structural reliability of SCC structures is not systematically conducted yet.

The purpose of this study is to perform the reliability and sensitivity assessments of the SCC beams considering the effects of metal corrosion. An algorithm using Monte Carlo simulation is proposed to utilize in analyses and assessments. The safety deterioration of SCC beams due to the corrosion phenomenon until 50 years is obtained. In addition, the effects of input random parameters on the safe condition of structures are evaluated based on Sobol's indices.

\section{Theoretical Backgrounds}

2.1. Sensitivity Definition. Sensitivity presents the influence of input design parameters (variables) $X=\left(X_{1}, X_{2}, \ldots, X_{m}\right)$ on the output model, $Y=f(X)$, where $X=\left(X_{1}, X_{2}, \ldots, X_{m}\right)$ is the vector of design parameters in space $\mathbb{R}^{m}$ and $Y=$ $\left(Y_{1}, Y_{2}, \ldots, Y_{n}\right)$ is the vector of output value in space $\mathbb{R}^{n}$. Sensitivity analysis describes how the uncertainty of modeling inputs $\left(X_{i}\right)$ affects the modeling output $(Y)$. There are two main classes of sensitivity analysis methods, which are local and global sensitivity. In this paper, we are going to apply the global sensitivity analysis for evaluating the reliability of SCC beams, in which the Sobol indices [29] are employed.

2.2. Global Sensitivity Analysis Using Sobol's Method. Consider an integral function, $Y=f(X)$, which can be decomposed into the elementary functions, as follows [30]:

$$
\begin{aligned}
f(X)= & f_{0}+\sum_{i} f_{i}\left(X_{i}\right)+\sum_{i<j} f_{i j}\left(X_{i}, X_{j}\right) \\
& +\cdots+f_{1, \cdots, m}\left(X_{1}, \ldots, X_{m}\right),
\end{aligned}
$$

where $X_{i}$ is the input random variables and independent probability; the variance of the output variable can be expressed as $[24,30,31]$

$$
\operatorname{Var}[Y]=\sum_{i=1}^{m} V_{i}+\sum_{1 \leq i<j \leq m}^{m} V_{i j}+\ldots+V_{1, \ldots, m},
$$

where

$$
\begin{aligned}
V_{i} & =\operatorname{Var}\left[E\left[Y \mid X_{i}\right]\right], \\
V_{i j} & =\operatorname{Var}\left[E|Y| X_{i} X_{j}\right]-V_{i}-V_{j}, \\
V_{1 \ldots n} & =\operatorname{Var}[Y]-\sum_{i=1}^{m} V_{i}-\sum_{1 \leq i<j \leq m}^{m} V_{i j}-\sum_{1 \leq i_{1}<\ldots<i_{n-1} \leq m}^{m} V_{i_{1} \ldots i_{m-1}} .
\end{aligned}
$$

The first-order Sobol's indices are determined by

$$
S_{i}=\frac{V_{i}}{\operatorname{Var}[Y]}
$$

The second-order Sobol's indices are determined by

$$
S_{i}=\frac{V_{i j}}{\operatorname{Var}[Y]}
$$

Total-effect Sobol's indices are then determined by

$$
S_{T i}=S_{i}+S_{i j}+S_{i k l}+\ldots+S_{i \ldots n} .
$$

In this research, Sobol's indices of global sensitivity by Monte Carlo simulation [32, 33] are estimated by establishing an algorithm in MATLAB, as presented in Section 4.

\subsection{Reliability Assessment by Monte Carlo Simulation.} The Monte Carlo simulation method is based on the use of pseudorandom numbers and the law of large numbers to assess the reliability of engineering systems. If the safe domain is defined by the condition $f(X)>0$, where $X$ is a random vector containing all the input random variables, the unsafe probability of the system is determined by

$$
\begin{aligned}
P_{f} & =\int I_{f(X)<0} f_{X}(x) \mathrm{d} x, \\
& =E\left[I_{f(X)<0}\right],
\end{aligned}
$$

where $I_{f(X)<0}$ is the indicator function and is defined by

$$
I_{f(X)<0}= \begin{cases}1, & \text { if } f(X) \leq 0 \\ 0, & \text { if } f(X)>0\end{cases}
$$

According to the theory of statistics, if we have $N$ realizations of the random vector $X$, by propagating the randomness, we can obtain a sample of $N$ realizations of the indicator function. The expected value of the indicator function can be approximately determined by taking the mean of the sample, expressed as 


$$
\widehat{P}_{f}=E\left[I_{f(X)<0}\right]=\frac{1}{N} \sum_{i=1}^{N} I_{f(X)<0}^{i} .
$$
[34]

A $95 \%$ confidence interval of the estimation is defined by

$$
\widehat{P}_{f}\left(1-1.96 \sqrt{\frac{1-\widehat{P}_{f}}{N \widehat{P}_{f}}}\right) \leq P_{f} \leq \widehat{P}_{f}\left(1+1.96 \sqrt{\frac{1-\widehat{P}_{f}}{N \widehat{P}_{f}}}\right) .
$$

The algorithm for reliability assessment based on the Monte Carlo simulation is developed using MATLAB, as presented in Section 4.

2.4. Corrosion Modeling. Atmospheric corrosion of steel structures in various environments was intensively studied and proposed by Komp [35]. We adopted this corrosion model to evaluate the reliability of corroded SCC beams in this study. Corrosion models usually describe the corrosion depth as a function of time in the form of a power model and can be written as follows:

$$
\mathrm{d}(t)=A t^{B}
$$

where $\mathrm{d}(t)$ is the corrosion depth $\left(\mu \mathrm{m}, \mathrm{g} / \mathrm{m}^{2}\right), t$ is the exposure time (year), $A$ is the corrosion rate in the first year of exposure, and $B$ is the corrosion rate of long-term decrease. $A$ and $B$ are dependent on the environment where the structure is located and they are presented in Table 1 . The modeling in equation (12) and average values for corrosion parameters in Table 1 have been also used in some studies elsewhere [36, 37].

\section{Design Procedure of the SCC Beam}

The SCC beam used in this study has been designed according to EC-4 [38]. The safe condition of SCC beams must be satisfied: (1) ultimate limit state and (2) serviceability limit state. Those limit states can be referred to Sections 6 and 7 of EC- 4 and it can be expressed as follows:

$$
S_{d} \leq R_{d}
$$

where $S_{d}$ is the calculated demand due to applied loads and $R_{d}$ is the resistance (capacity) of the component (i.e., design strength) determined by equation (14), expressed as

$$
R_{d}=R_{d}\left(\frac{f_{y}}{\gamma_{a}}, \frac{f_{c k}}{\gamma_{c}}, \frac{f_{y s}}{\gamma_{s}}, \frac{f_{y p}}{\gamma_{a p}}\right)
$$

where $f_{y}, f_{c k}$ are the nominal yield strength of steel and compressive characteristic strength of concrete, respectively; $f_{y s}$ and $f_{y p}$ are the yield strength of structural steel and profiled steel sheeting, respectively; and $\gamma_{a}, \gamma_{c}, \gamma_{s}, \gamma_{a p}$ are the partial factors of structural steel, concrete, reinforcing steel, and profiled steel sheeting, respectively. The design procedure of SCC beams is illustrated in Figure 1.
3.1. Shear Resistance. The shear resistance of the SCC beam is similar to that of the steel beam since the shear resistance of the concrete slab can be negligible. Shear stress in the steel section web should not exceed the shear strength of steel; reliability criterion is shown in equation (15):

$$
\begin{aligned}
\frac{\tau_{\mathrm{Ed}} \cdot \gamma_{M 0}}{f_{y} / \sqrt{3}} & \leq 1.0, \\
\tau_{\mathrm{Ed}} & =\frac{V_{\mathrm{Ed}} \cdot S_{y}}{I_{y} \cdot t_{w}},
\end{aligned}
$$

where $\tau_{\mathrm{Ed}}$ is the shear stress in the steel section web, $\gamma_{M 0}$ is the partial factor for steel applied to the resistance of the cross section, $V_{E d}$ is the design value of the shear force acting on the composite section, $s_{y}$ is the longitudinal spacing center-to-center of the stud shear connectors, $I_{y}$ is the second moment of the steel area, $t_{w}$ is the thickness of the web of the steel section.

3.2. Bending Resistance. The normal stress in the steel section flanges should not exceed the yield strength of steel, while the normal stress in the concrete slab should not exceed the compressive strength of concrete. The calculation is carried out with an effective width of concrete slab, $b_{\text {eff }}$ (Figure 2), calculated by

$$
b_{\mathrm{eff}}=b_{e 1}+b_{e 2}
$$

where $b_{e i}=\min \left(\left(l_{0} / 8\right), b_{i}\right)$.

Three cases to be considered for I-shaped sections are presented in Figure 3, where the plastic neutral axis (PNA) is varied on the cross section of the SSC beam.

Case 1. PNA lies in the concrete slab. $M_{\mathrm{pl}, \mathrm{Rd}}$ is the plastic moment resistance of the composite beam and is calculated according to EC-4, expressed by

$$
M_{\mathrm{pl}, \mathrm{Rd}}=F_{a}\left(\frac{h_{a}}{2}+h_{c}+h_{p}-\frac{z}{2}\right) \text {. }
$$

Case 2. PNA lies in the steel flange. $M_{\mathrm{pl}, \mathrm{Rd}}$ is the plastic moment resistance of the composite beam and is calculated by

$$
M_{\mathrm{pl}, \mathrm{Rd}}=F_{a}\left(\frac{h_{a}}{2}+h_{c}+h_{p}-\frac{z}{2}\right)-\frac{1}{2} \cdot\left(F_{a}-F_{c}\right)\left(z+h_{p}\right) .
$$

Case 3. PNA lies in the steel flange. $M_{\mathrm{pl}, \mathrm{Rd}}$ is the plastic moment resistance of the composite beam and is calculated by

$$
M_{\mathrm{pl}, \mathrm{Rd}}=M_{\mathrm{apl}, \mathrm{Rd}}+F_{c}\left(\frac{h_{a}}{2}+\frac{h_{c}}{2}+h_{p}\right)-\frac{F_{c}^{2}}{4 t_{w}\left(f_{y} / \gamma_{a}\right)},
$$


TABLE 1: Average values of corrosion parameters $A$ and $B$ for carbon and weathering steel.

\begin{tabular}{lcccr}
\hline \multirow{2}{*}{ Environment } & \multicolumn{2}{c}{ Carbon steel } & \multicolumn{2}{c}{ Weathering steel } \\
& $A$ & $B$ & $A$ & 33.3 \\
Rural & 34.0 & 0.65 & 50.7 & 0.50 \\
Urban & 80.2 & 0.59 & 40.2 & 0.57 \\
Marine & 70.6 & 0.79 & 0.56 \\
\hline
\end{tabular}

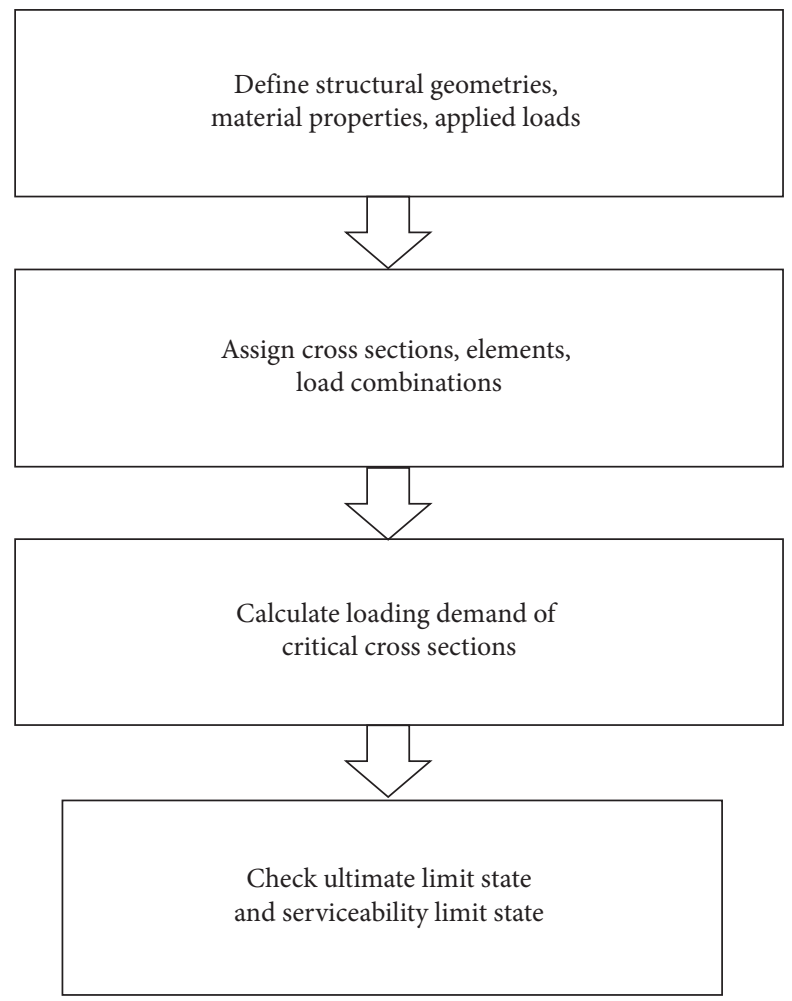

FIGURE 1: Procedure for designing of the SCC beam.

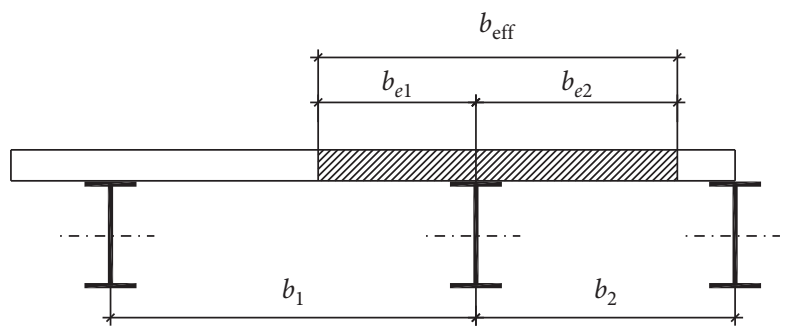

FIGURE 2: Procedure for designing of the SCC beam.

where $F_{a}=\left(A_{a} f_{y} / \gamma_{a}\right)$ is the plastic strength of the steel section and $F_{c}=h_{c} \cdot b_{\text {eff }}\left(0.85 f_{\mathrm{ck}} / \gamma_{c}\right)$ is the strength of the concrete slab.

3.3. Deflection at the Serviceability Limit State. Overall, the deflection of the composite beam depends on the way of fractioning. In the case of fractioning without intermediate supports, applied loads can be imposed on the steel section without the composite effect or the loads directly subject on the composite section:

$$
\frac{w}{w_{\lim }} \leq 1.0
$$

where $w$ is the overall deflection and $w_{\lim }$ is the limit value of deflection according to EC-4.

\section{Reliability Analysis of SCC Beams}

The reliability of SCC beams is assessed based on the combination of the deterministic and uncertainty models, in which the randomness of input parameters is considered. 


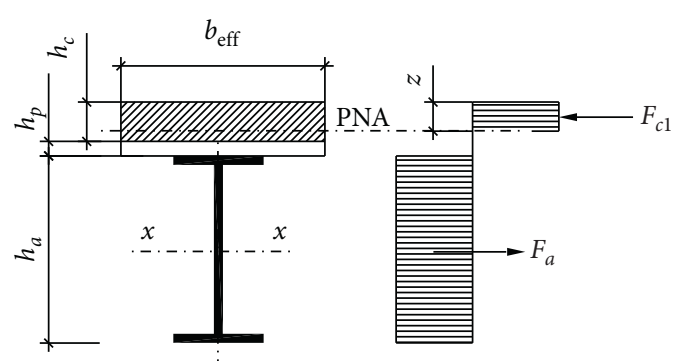

(a)

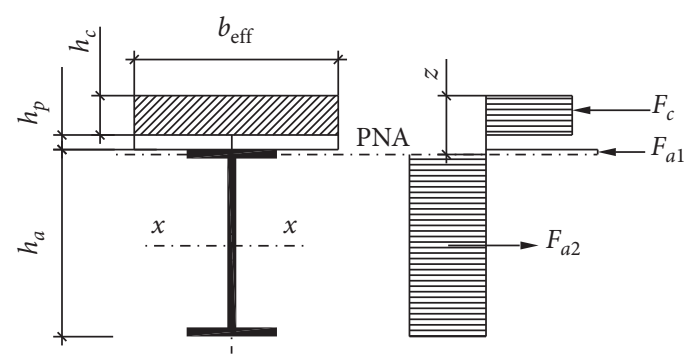

(b)

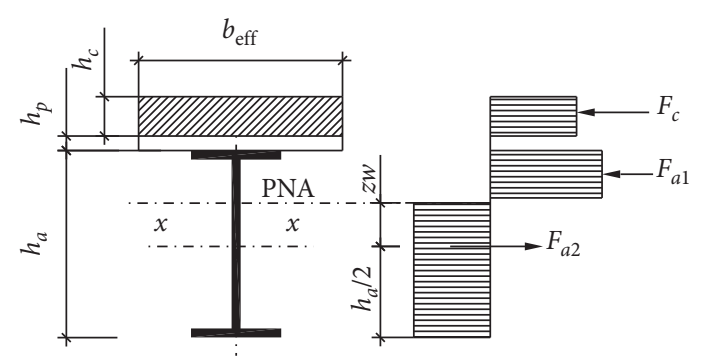

(c)

Figure 3: Plastic design of the steel-reinforced concrete beams: (a) when PNA lies in concrete slab; (b) when PNA lies in steel flange; and (c) when PNA lies in steel web.

The effects of input variables on the reliability are evaluated based on the sensitivity. For that, the global sensitivity Sobol's indices and Monte Carlo simulations are employed for sensitivity and reliability analyses. The proposed algorithms of sensitivity and reliability analyses, verification, and relevant conditions are described as follows.

4.1. Safe Condition. According to EC-4, the safe conditions of the SCC beam must satisfy the ultimate limit state and serviceability limit state. The safe conditions can be rewritten as follows:

$$
M_{\mathrm{saf}}=\left\{\begin{array}{l}
\frac{\tau_{\mathrm{Ed}} \cdot \gamma_{M 0}}{\left(f_{y} / \sqrt{3}\right)} \leq 1.0, \\
\frac{M_{\mathrm{pl}, \mathrm{Rd}}}{M_{\mathrm{Ed}}} \leq 1.0 \text { (ultimate limit state), } \\
\frac{w}{w_{\text {lim }}(\text { serviceability limit state) }},
\end{array}\right.
$$

where $M_{\text {saf }}$ is the safe conditions based on EC-4.

4.2. Deterministic and Uncertainty Models. The deterministic model deals with the safe conditions of SCC beams, in which the input random variables are those of geometry $\left(L, b\right.$, IPE), material properties $\left(f_{c k}, f_{u}\right)$, and applied loads $(g)$. This model can be written as equation (23) with function $X=\left[L, b, \mathrm{IPE}, f_{c k}, f_{u}, g\right]$ :

$$
M_{\text {saf }}=\mathfrak{I}(X) .
$$

The uncertainty model is constructed based on the deterministic model accounting for the randomness of some input variables. In this paper, we distinct two vectors of input parameters: (1) the parameters assumed to be deterministic, $X_{1}=[L, b, g]$, and (2) the parameters assumed to be random variable, $X_{2}(\omega)=\left[f_{c k}(\omega), f_{u}(\omega), \operatorname{IPE}(\omega)\right]$, where $\omega$ represents the randomness of the parameters. This model can be written as

$$
M_{\text {saf }}=\mathfrak{J}\left(X_{1}, X_{2}(\omega)\right) .
$$

4.3. Reliability Assessment of Corroded SCC Beams Using Monte Carlo Simulation. The reliability assessment of corroded SCC beams based on EC-4 is developed in MATLAB using the Monte Carlo simulation method. The flowchart of the reliability assessment of the composite beam is shown in Figure 4.

\subsubsection{Global Sensitivity Analysis by Monte Carlo Simulation.} The sensitivity analysis for corroded SCC beams has been performed based on the global Sobol's sensitivity indices. The Monte Carlo simulation method is established in MATLAB and the algorithm is shown in Figure 5.

Validation of the global sensitivity Sobol's indices by Monte Carlo simulation is performed using the Ishigami test function, defined as follows [39]:

$$
Y(X)=\sin X_{1}+7 \sin ^{2} X_{2}+\frac{1}{10} X_{3}^{4} \sin X_{1}
$$

where $X_{1}, X_{2}, X_{3}$ are the uniform distributions between- $\pi$ and $\pi$. The results of the proposed algorithm and the results of Morio [30] are shown in Table 2. It is found that the comparison of those results is in good agreement. The small errors in Table 2 confirm the capability of the proposed program. 


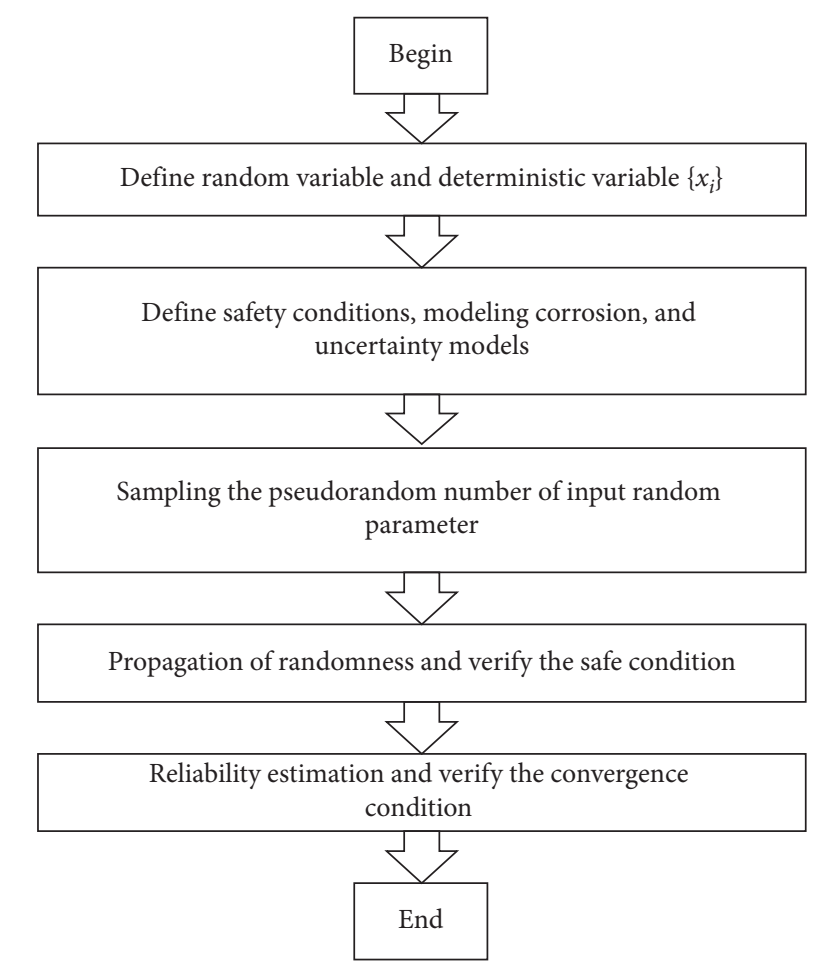

FIGURE 4: Flowchart of the reliability assessment of SCC beams using Monte Carlo simulation.

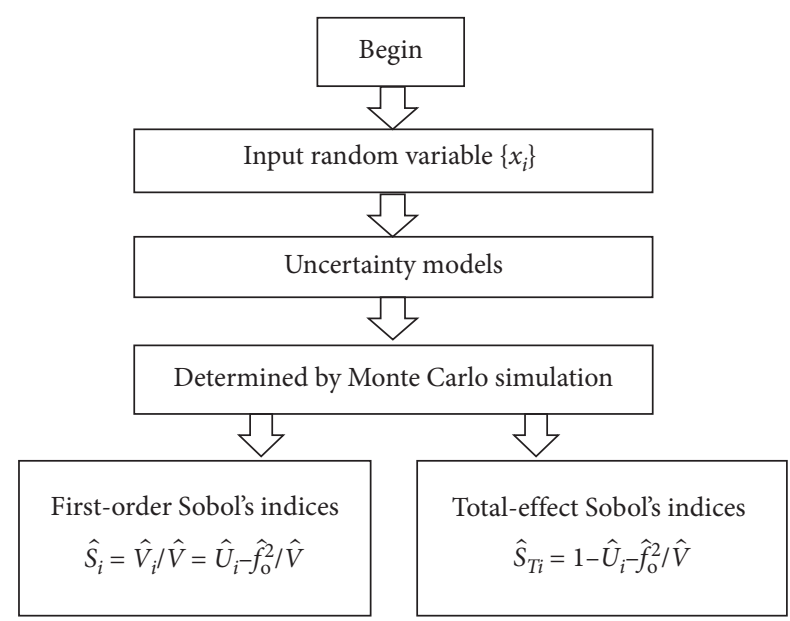

FIGURE 5: Flowchart of Sobol's indices sensitivity analysis by Monte Carlo simulation.

TABle 2: Mean estimation with 10,000 Monte Carlo samples of the first and total Sobol's indices.

\begin{tabular}{|c|c|c|c|c|c|c|}
\hline \multirow{2}{*}{$X_{\mathrm{i}}$} & \multicolumn{2}{|c|}{ This study } & \multicolumn{2}{|c|}{$\begin{array}{c}\text { Result of Morio } \\
{[30]}\end{array}$} & \multicolumn{2}{|c|}{ Error (\%) } \\
\hline & $S_{i}$ & $S_{T i}$ & $S_{i}$ & $S_{T i}$ & $S_{i}$ & $S_{T i}$ \\
\hline$X_{1}$ & 0.315 & 0.577 & 0.313 & 0.576 & $0.63 \%$ & $0.17 \%$ \\
\hline$X_{2}$ & 0.432 & 0.440 & 0.434 & 0.438 & $0.46 \%$ & $0.45 \%$ \\
\hline$X_{3}$ & 0.001 & 0.258 & 0.001 & 0.254 & $0.00 \%$ & $1.55 \%$ \\
\hline
\end{tabular}

4.3.2. Validation of the SCC Beams. Validation of the proposed reliability assessment algorithm for SCC beams is presented. To validate the developed program, we consider an SCC beam example in Hoi [40], as shown in Figure 6. The input parameters for the design problem are presented in Table 3. The obtained results are compared in Table 4. The small errors in Table 4 confirm the capability and reliability of the proposed program in this study.

\section{Reliability Analysis of Corroded SCC Beams}

This study uses a convergence criterion of $2.0 \%$ to apply for reliability analyses. The number of simulations and elapsed analysis times is automatically determined when the convergence criterion is smaller than $2.0 \%$ after 20 consecutive simulations. Here, we analyze the sensitivity and reliability analyses of corroded SCC beams accounting for different corrosion levels including pristine, 10-year, 20-year, and 50year conditions. Detailed performances of investigated cases are presented as follows.

5.1. Structural Reliability and Sensitivity at the Pristine Condition. The proposed procedure is applied for the reliability assessment of SCC beams at the pristine condition (i.e., $t=0$ ). The nominal and distribution of input random variables are shown in Table 5. The nominal and distribution of material properties are based on the propose of Bartlett et al. [41], and the cross section and loading are adopted from the study of Ellingwood et al. [42]. The cross sections of steel-reinforced concrete beams for investigating are shown in Figure 7. All input random variables are shown in Table 6.

Figure 8 shows the convergence of the safety probability of the SCC beams at the design time $(t=0)$ in the Monte Carlo simulation. The safe probability $\left(P_{s}\right)$ reaches 0.9796 after 3,740 samplings with 15 mins running. The used convergence criteria of $2.0 \%$ justify the confidence of the estimated reliability. This result also implies that although we have taken the safety factor of 1.1 in the analysis, because of the randomness of input parameters, the reliability of the structure is only of $97.96 \%$. Therefore, the assessment of the reliability of the structure is necessary, especially considering the metal corrosion over operating time.

The global sensitivity based on Sobol's sensitivity indices is applied to evaluate the influence of input random variables on the total safe condition of the SCC beam at the pristine condition. Table 7 and Figure 9 show the influence of input random variables on the first and total safe conditions of SCC beams at the initial time using Sobol's sensitivity indices. It can be seen that the compressive strength of concrete $\left(f_{c k}\right)$ and the ultimate strength of steel $\left(f_{u}\right)$ are the most influential variables with a proportion of $41.0 \%$ and $48.0 \%$ for the first-order Sobol's sensitivity indices, respectively. A similar tendency is observed for the total sensitivity indices, in which superior proportions of $f_{c k}$ and $f_{u}$ are $43.0 \%$ and $50.0 \%$, respectively. Meanwhile, the weakest influence variables are $b_{f}$ and $t_{f}$ with a proportion of less than $1.0 \%$. This is consistent with the qualitative concept and that shows the importance of sensitivity analysis at the designing time. 


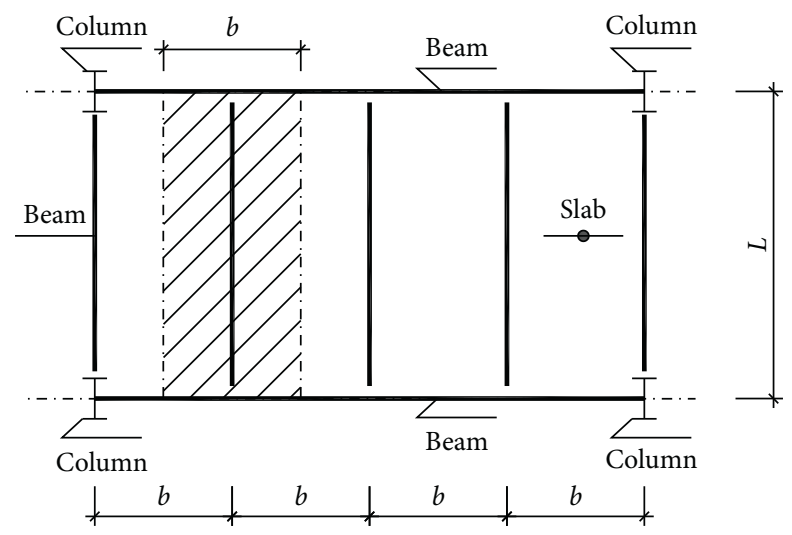

FIGURE 6: An SCC beam for validation of the proposed algorithm.

TABLE 3: Input parameters of the SCC beam for validating the proposed algorithm.

\begin{tabular}{|c|c|c|c|c|c|}
\hline$L$ & $b$ & $g^{*}$ & $f_{c k}$ & $f_{u}$ & IPE \\
\hline$(\mathrm{m})$ & (m) & $\left(\mathrm{kN} / \mathrm{m}^{2}\right)$ & $\left(\mathrm{N} / \mathrm{mm}^{2}\right)$ & $\left(\mathrm{N} / \mathrm{mm}^{2}\right)$ & (S235) \\
\hline 10.00 & 3.50 & 14.70 & 25.00 & 450.0 & 400 \\
\hline
\end{tabular}

${ }^{*}$ Loads combination of the overall dead load $\left(g_{k}\right)$ and the service load on the floor $\left(q_{k}\right)$

TABLE 4: Comparison of the results obtained in this study and in Hoi [40].

\begin{tabular}{lcccc}
\hline Calculated parameter & Unit & Result of Hoi [40] & This study & Error (\%) \\
\hline$b_{e}$ & $\mathrm{~mm}$ & 2,500 & 2,500 & 0.000 \\
$M_{\mathrm{Ed}}$ & $\mathrm{kN}-\mathrm{m}$ & 540 & 540 & 0.000 \\
$V_{\mathrm{Ed}}$ & $\mathrm{kN}$ & 216 & 216 & 0.000 \\
$M_{\mathrm{pl}, \mathrm{Rd}}$ & $\mathrm{kN}-\mathrm{m}$ & 540.02 & 540 & 0.004 \\
$V_{\mathrm{pl}, \mathrm{Rd}}$ & $\mathrm{kN}$ & 452.60 & 452.50 & 0.022 \\
\hline
\end{tabular}

TABLE 5: Statistical properties of random variables for reliability assessment of SCC beams.

\begin{tabular}{|c|c|c|c|c|c|c|}
\hline Properties & Variables & Nominal & Mean/nominal & $\mathrm{COV}$ & Distribution & Ref. \\
\hline Material & $\begin{array}{l}f_{c k} \\
f_{u}\end{array}$ & $\begin{array}{c}25\left(\mathrm{~N} / \mathrm{mm}^{2}\right) \\
450\left(\mathrm{~N} / \mathrm{mm}^{2}\right)\end{array}$ & $\begin{array}{l}1.10 \\
1.10\end{array}$ & $\begin{array}{l}0.06 \\
0.06\end{array}$ & $\begin{array}{l}\text { Lognormal } \\
\text { Lognormal }\end{array}$ & $\begin{array}{l}41] \\
{[41]}\end{array}$ \\
\hline Loading & $\begin{array}{l}g_{k} \\
q_{k}\end{array}$ & $\begin{array}{c}9.54(\mathrm{kN} / \mathrm{m}) \\
13.69(\mathrm{kN} / \mathrm{m})\end{array}$ & $\begin{array}{l}1.05 \\
1.05 \\
\end{array}$ & $\begin{array}{l}0.10 \\
0.10\end{array}$ & $\begin{array}{l}\text { Normal } \\
\text { Normal }\end{array}$ & $\begin{array}{l}{[42]} \\
{[42]}\end{array}$ \\
\hline Cross section IPE 400 & $\begin{array}{c}b_{f} \\
t_{f} \\
h_{a} \\
t_{w} \\
R\end{array}$ & $\begin{array}{l}180(\mathrm{~mm}) \\
13.5(\mathrm{~mm}) \\
400(\mathrm{~mm}) \\
8.6(\mathrm{~mm}) \\
21(\mathrm{~mm})\end{array}$ & $\begin{array}{l}1.00 \\
1.00 \\
1.00 \\
1.00 \\
1.00\end{array}$ & $\begin{array}{l}0.05 \\
0.05 \\
0.05 \\
0.05 \\
0.05\end{array}$ & $\begin{array}{l}\text { Normal } \\
\text { Normal } \\
\text { Normal } \\
\text { Normal } \\
\text { Normal }\end{array}$ & $\begin{array}{l}{[42]} \\
{[42]} \\
{[42]} \\
{[42]} \\
{[42]}\end{array}$ \\
\hline
\end{tabular}
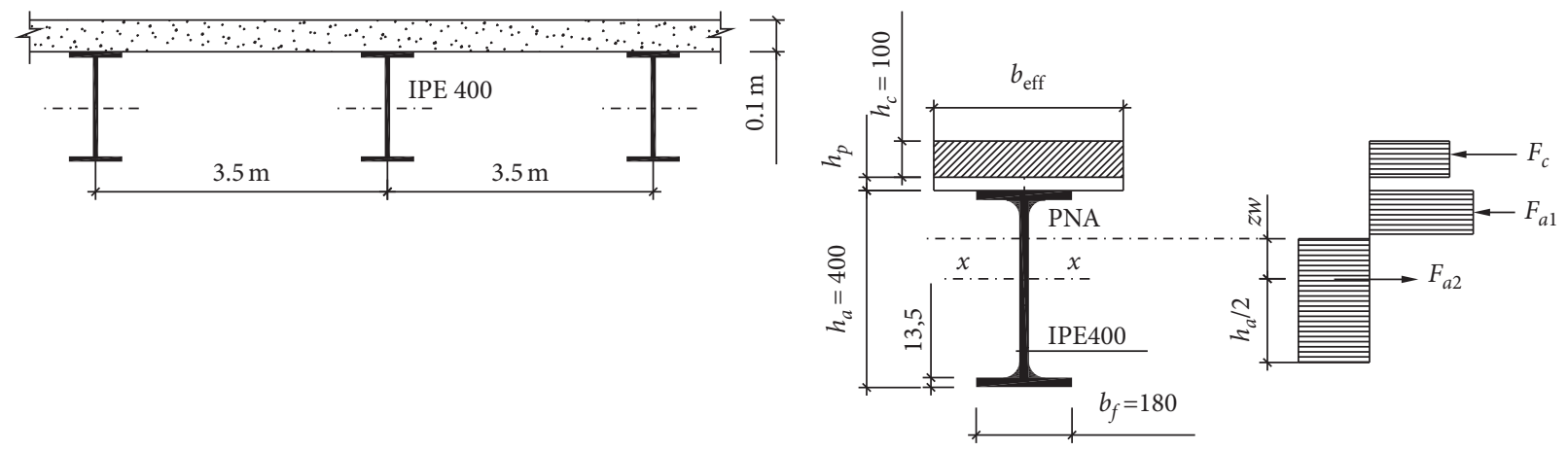

(a)

(b)

Figure 7: Cross section of slabs (a) and stress distribution of the cross section (b). 
TABLE 6: Statistical properties of random variables for Sobol's indices sensitivity analysis.

\begin{tabular}{|c|c|c|c|c|}
\hline Properties & Variables & Distribution & Range & Units \\
\hline Material & $\begin{array}{l}f_{c k} \\
f_{u}\end{array}$ & $\begin{array}{l}\text { Uniform } \\
\text { Uniform }\end{array}$ & $\begin{array}{c}22.5-27.5 \\
405-495 \\
\end{array}$ & $\begin{array}{l}\mathrm{N} / \mathrm{mm}^{2} \\
\mathrm{~N} / \mathrm{mm}^{2}\end{array}$ \\
\hline Loading & $\begin{array}{l}g_{k} \\
q_{k}\end{array}$ & - & $\begin{array}{c}9.54 \\
13.69 \\
\end{array}$ & $\begin{array}{l}\mathrm{kN} / \mathrm{m} \\
\mathrm{kN} / \mathrm{m}\end{array}$ \\
\hline Cross section IPE 400 & $\begin{array}{c}b_{f} \\
t_{f} \\
h_{a} \\
t_{w} \\
R\end{array}$ & $\begin{array}{c}\text { Uniform } \\
\text { Uniform } \\
\text { Uniform } \\
\text { Uniform } \\
\quad-\end{array}$ & $\begin{array}{c}162-198 \\
12.15-14.85 \\
360-440 \\
7.74-9.46 \\
21\end{array}$ & $\begin{array}{l}\mathrm{mm} \\
\mathrm{mm} \\
\mathrm{mm} \\
\mathrm{mm} \\
\mathrm{mm}\end{array}$ \\
\hline
\end{tabular}

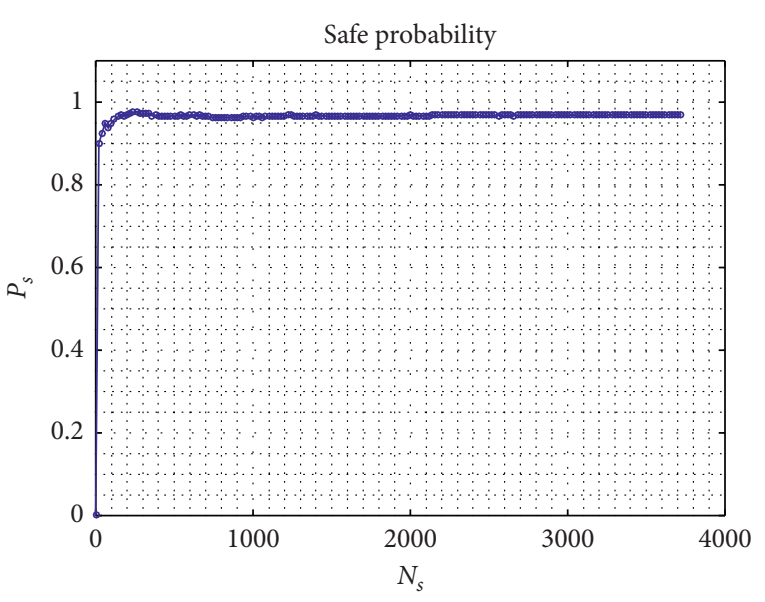

(a)

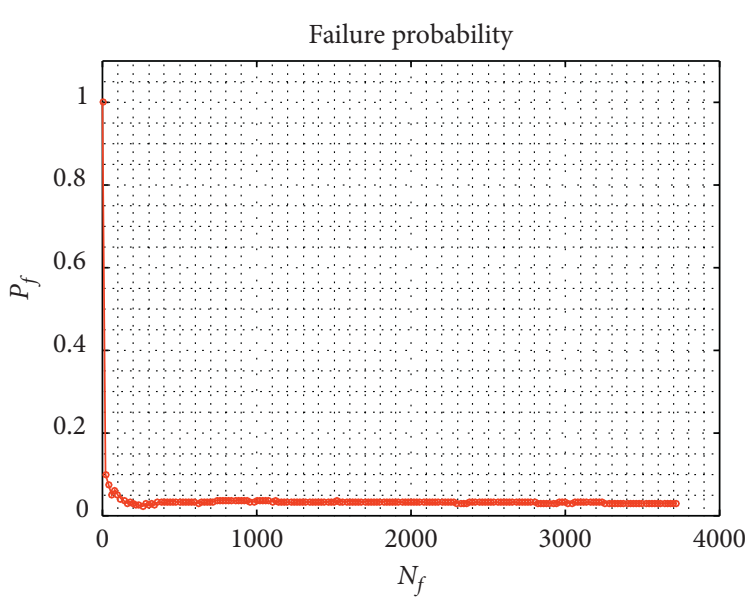

(b)

FIgURE 8: Convergence of the safe probability of the SCC beams at the design time $(t=0)$.

TABle 7: Mean estimation with 200,000 Monte Carlo samples of first and total Sobol's indices.

\begin{tabular}{lcc}
\hline Variable & First-order sensitivity Sobol's indices & Total sensitivity Sobol's indices \\
\hline$X_{1}\left(t_{w}\right)$ & 0.0591 & 0.0478 \\
$X_{2}\left(h_{a}\right)$ & 0.0301 & 0.0192 \\
$X_{3}\left(b_{f}\right)$ & 0.0135 & 0.0011 \\
$X_{4}\left(t_{f}\right)$ & 0.0141 & 0.0028 \\
$X_{5}\left(f_{c k}\right)$ & 0.4313 & 0.4270 \\
$X_{6}\left(f_{u}\right)$ & 0.5031 & 0.5050 \\
\hline
\end{tabular}

However, over time, the structural reliability of SCC beams will be reduced due to metal corrosion. Thus, the next sections deal with the reliability assessment of the SCC beam with a variation of corrosion times from 10 years to 50 years.

\subsection{Structural Reliability and Sensitivity after 10-Year} Corrosion. We here evaluate the safety probability of SCC beams considering metal corrosion after 10 years. The cross section of SCC beams is considered due to the corrosion according to Komp's model [35] in the urban environment. The nominal and distribution of material properties are adopted from Bartlett et al. [41] and the loading condition is adopted in Ellingwood et al. [42]. The convergence of the safe probability using the Monte Carlo simulation for the 10year corroded SCC beams is shown in Figure 10. The safety probability of the corroded SCC beams is 0.968 after about
3900 samplings with 20-minute running. Used convergence criteria of $2.0 \%$ justify the confidence of the estimated reliability. It can be seen that the safe probability has a decrease compared to that of the SCC beam at the pristine time. However, these decreases of safe probability are trivial in affecting the safety of the structure.

The global sensitivity based on Sobol's sensitivity indices is employed to assess the influence of input random variables on the total safety condition of 10 -year corroded SCC beams. A range of input uniform variables identified is approximately $90 \%$ to $110 \%$ of the mean value after being corroded. The results of Sobol's sensitivity indices are shown in Table 8 and Figure 11. Similarly, it can be observed that $f_{c k}$ and $f_{u}$ are the most influential input random variables. Their proportions are $40.0 \%$ and $51.0 \%$ for the first-order Sobol's sensitivity indices and $42.0 \%$ and $51.0 \%$ for the total sensitivity indices, respectively. Meanwhile, the uninfluential 


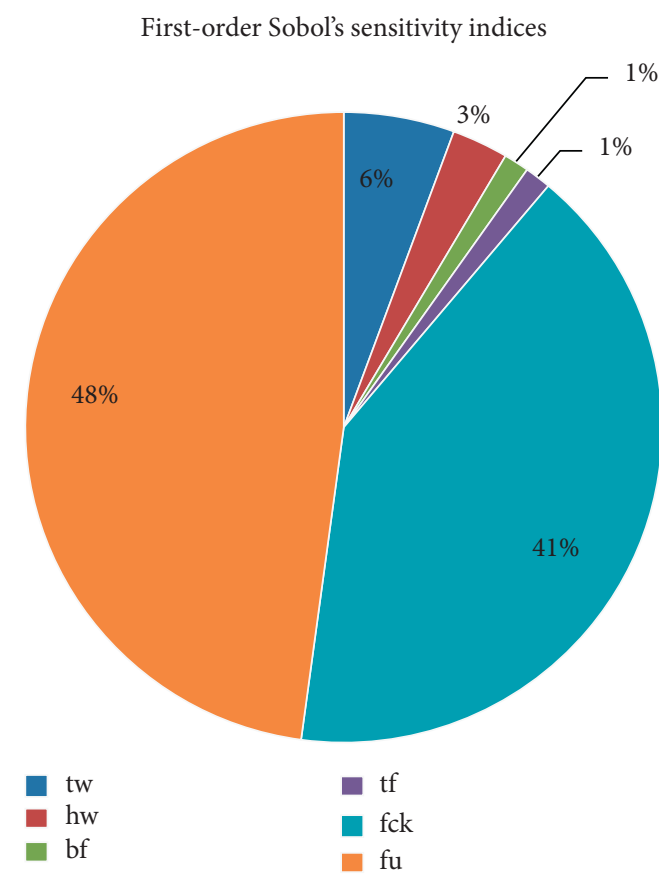

(a)

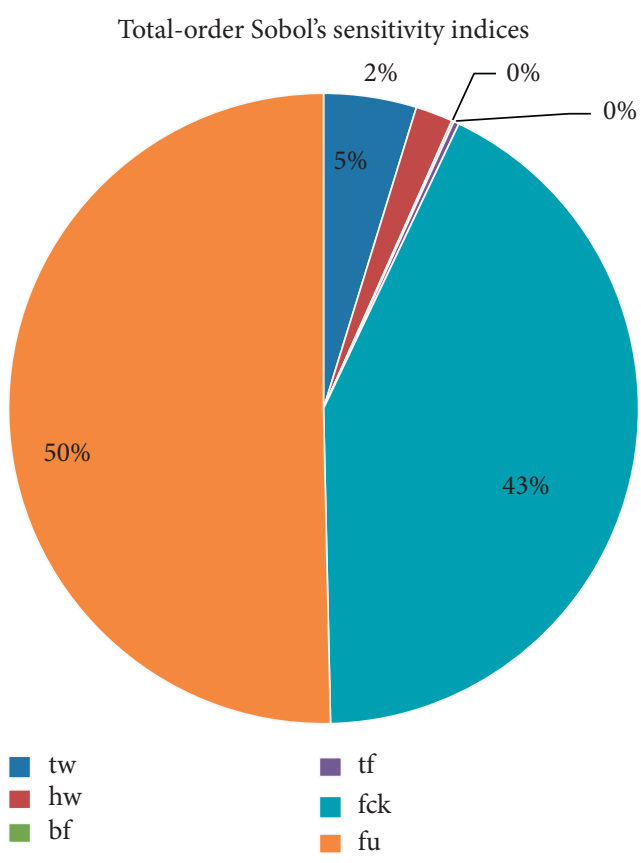

(b)

FIGURE 9: First-order and total Sobol's sensitivity indices of the SCC beams at the pristine condition.

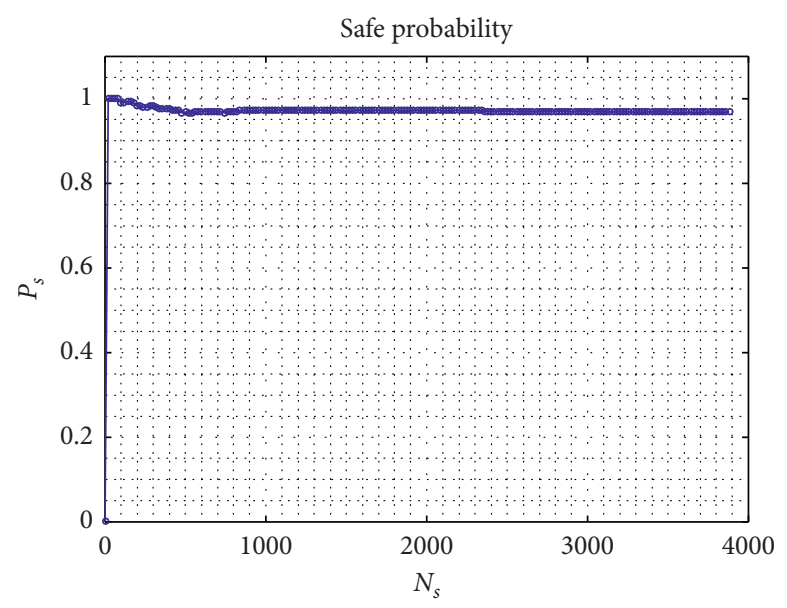

(a)

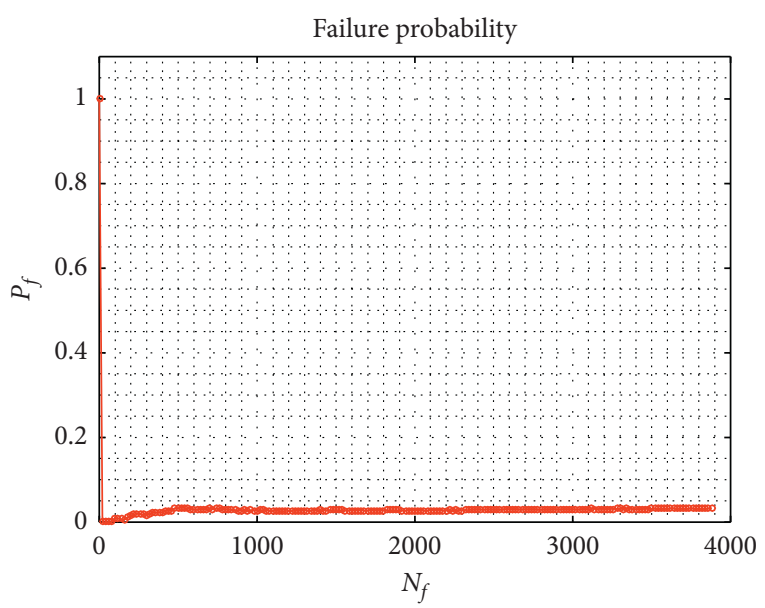

(b)

FIGURE 10: Convergence of the safe probability of the 10-year corroded SCC beams.

variables are $b_{\mathrm{f}}$ and $t_{\mathrm{f}}$ with proportions of less than $1.0 \%$. Also, $h_{w}$ has a minor sensitivity index, highlighting that it insignificantly affects the calculated reliability of the SCC beam.

5.3. Structural Reliability and Sensitivity after 20-Year Corrosion. Similarly, we evaluate the structural reliability of the SCC beam considering 20-year corrosion. The convergence of the safe probability of the 20-year corroded SCC beams using Monte Carlo simulation is shown in Figure 12.
The safety probability of the corroded composite beams is 0.9436 after about 3420 samplings with 12 minutes. It can be seen that the probability of safety of the 20 -year corroded beam has a decrease of $3.24 \%$ compared to that of the pristine case.

The global sensitivity based on Sobol's sensitivity indices is applied to evaluate the influence of input random variables on the total safety of the 20-year corroded SCC beam, as shown in Table 9 and Figure 13. It again can be seen that $f_{c k}$ and $f_{u}$ are the most influential input random variables with proportions of $38.0 \%$ and $48.0 \%$ for the first-order Sobol's 
TABLE 8: Mean estimation with 200,000 Monte Carlo samples of the first and total Sobol's indices for the 10-year corroded SCC beams.

\begin{tabular}{lcc}
\hline Variable & First-order sensitivity Sobol's indices & Total-order sensitivity Sobol's indices \\
\hline$X_{1}\left(t_{\mathrm{w}}\right)$ & 0.0535 & 0.047 \\
$X_{2}\left(h_{\mathrm{a}}\right)$ & 0.0244 & 0.0175 \\
$X_{3}\left(b_{f}\right)$ & 0.0093 & 0.0012 \\
$X_{4}\left(t_{\mathrm{f}}\right)$ & 0.0109 & 0.0030 \\
$X_{5}\left(f_{\mathrm{ck}}\right)$ & 0.4155 & 0.4143 \\
$X_{6}\left(f_{\mathrm{u}}\right)$ & 0.5232 & 0.5116 \\
\hline
\end{tabular}

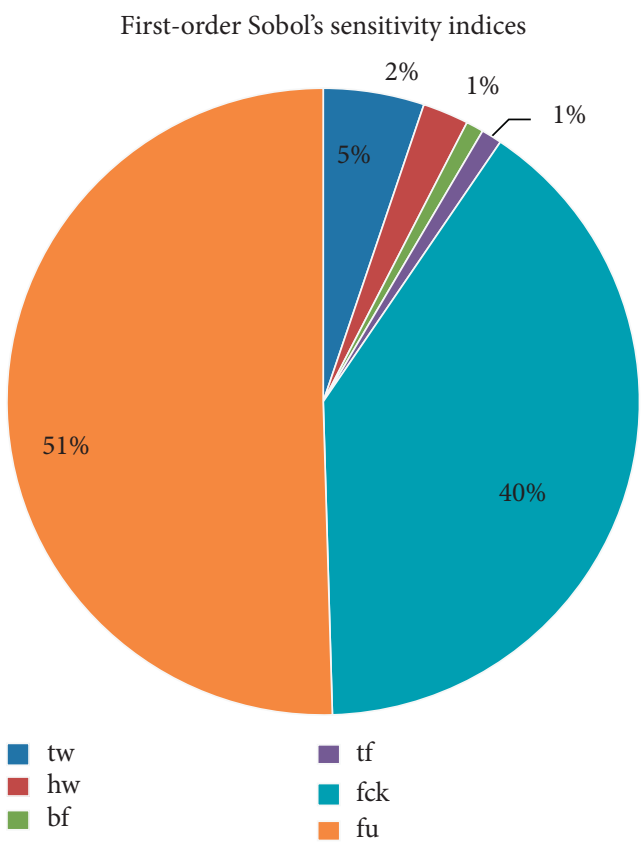

(a)

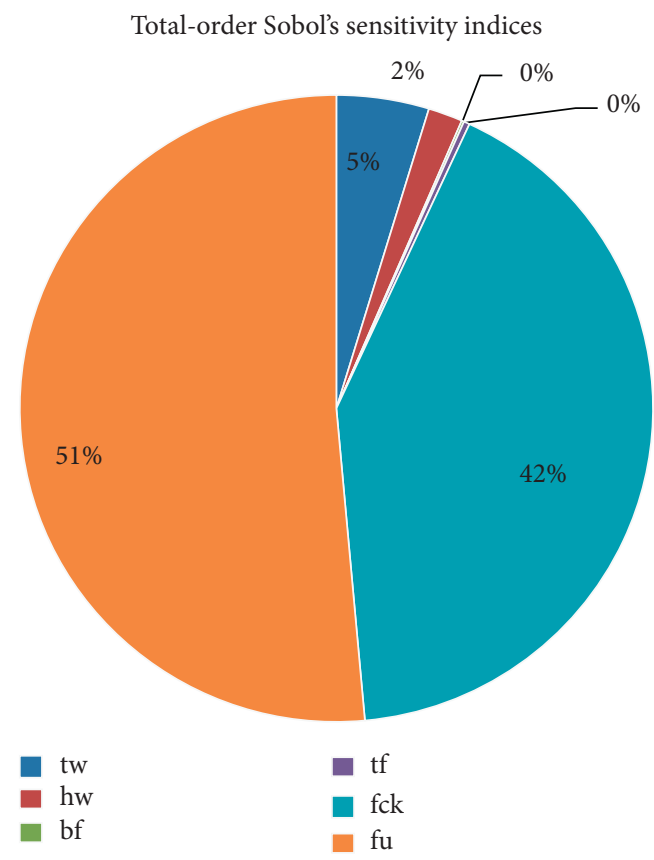

(b)

FIGURE 11: First-order and total Sobol's sensitivity indices of the 10-year corroded SCC beams.

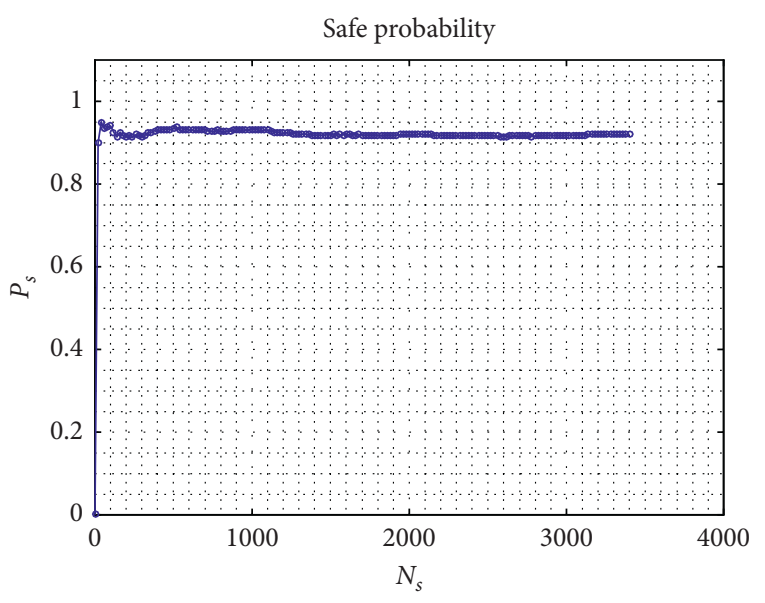

(a)

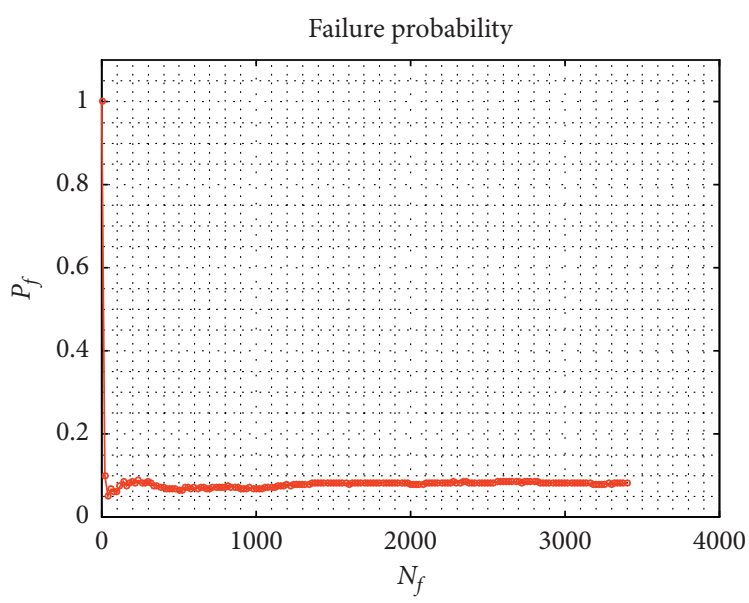

(b)

FIGURE 12: Convergence of the safe probability of the 20-year corroded SCC beams. 
TABle 9: Mean estimation with 200,000 Monte Carlo samples of the first and total Sobol's indices for the 20-year corroded SCC beams.

\begin{tabular}{lcc}
\hline Variable & First order sensitivity Sobol's indices & Total sensitivity Sobol's indices \\
\hline$X_{1}\left(t_{w}\right)$ & 0.1154 & 0.1166 \\
$X_{2}\left(h_{a}\right)$ & 0.0194 & 0.0154 \\
$X_{3}\left(b_{f}\right)$ & 0.0030 & 0.0014 \\
$X_{4}\left(t_{f}\right)$ & 0.0036 & 0.0023 \\
$X_{5}\left(f_{c k}\right)$ & 0.3808 & 0.3839 \\
$X_{6}\left(f_{u}\right)$ & 0.4847 & 0.4844 \\
\hline
\end{tabular}

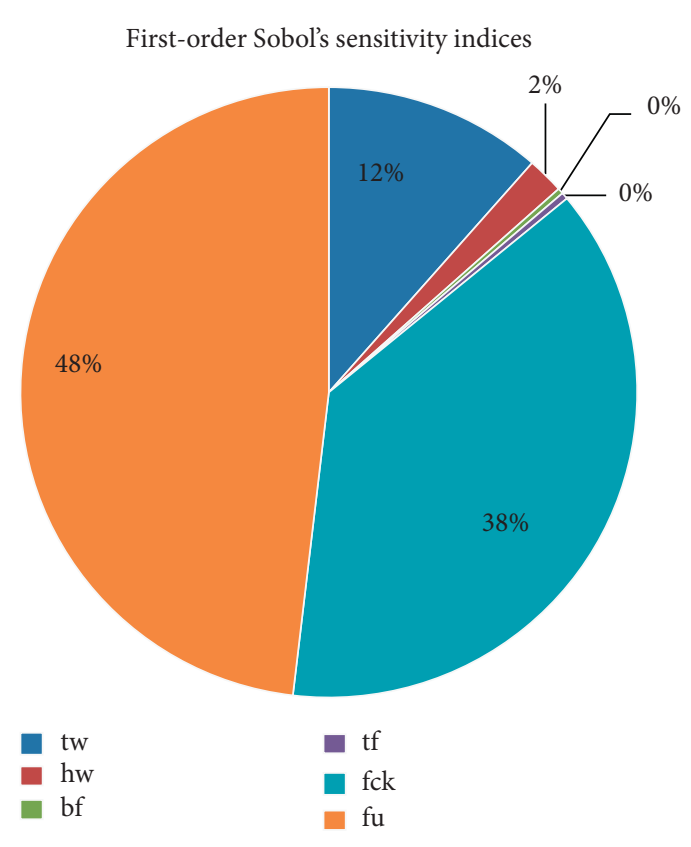

(a)
Total-order Sobol's sensitivity indices

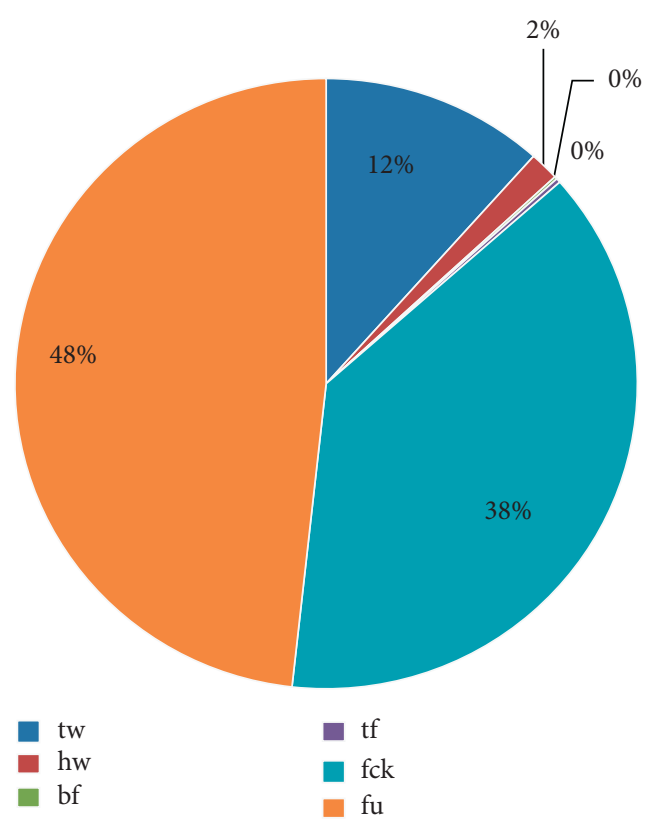

(b)

FIGURE 13: First-order and total Sobol's sensitivity indices of the 20-year corroded SCC beams.

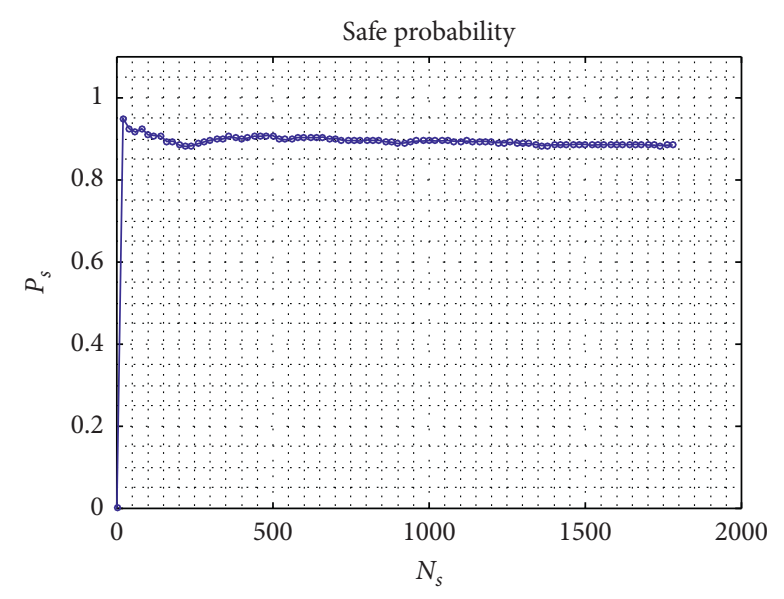

(a)

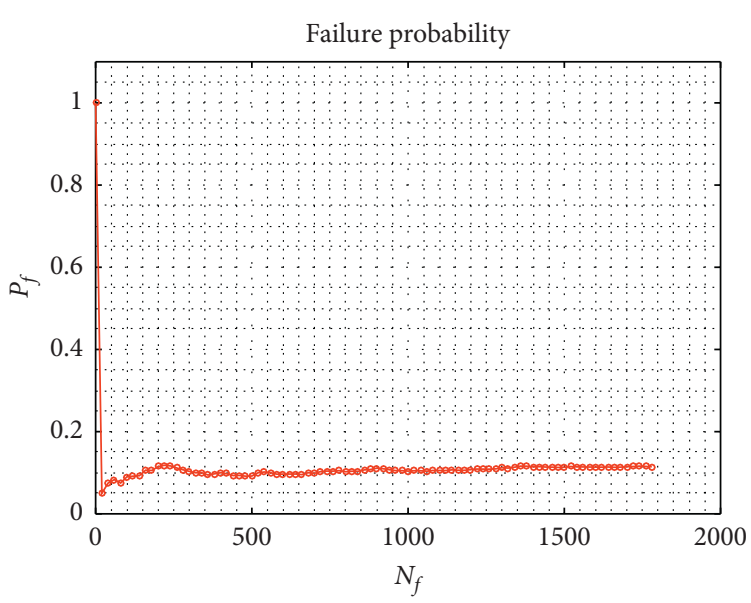

(b)

FIGURE 14: Convergence of the safe probability of the 50-year corroded SCC beams. 
TABle 10: Mean estimation with 200,000 Monte Carlo samples of the first and total Sobol's indices the 50-year corroded SCC beams.

\begin{tabular}{lcc}
\hline Variable & First-order sensitivity Sobol's indices & Total-order sensitivity Sobol's indices \\
\hline$X_{1}\left(t_{w}\right)$ & 0.1100 & 0.1452 \\
$X_{2}\left(h_{a}\right)$ & 0.0177 & 0.0143 \\
$X_{3}\left(b_{f}\right)$ & 0.0280 & 0.0016 \\
$X_{4}\left(t_{f}\right)$ & 0.0270 & 0.0026 \\
$X_{5}\left(f_{c k}\right)$ & 0.3589 & 0.3824 \\
$X_{6}\left(f_{u}\right)$ & 0.4518 & 0.4843 \\
\hline
\end{tabular}

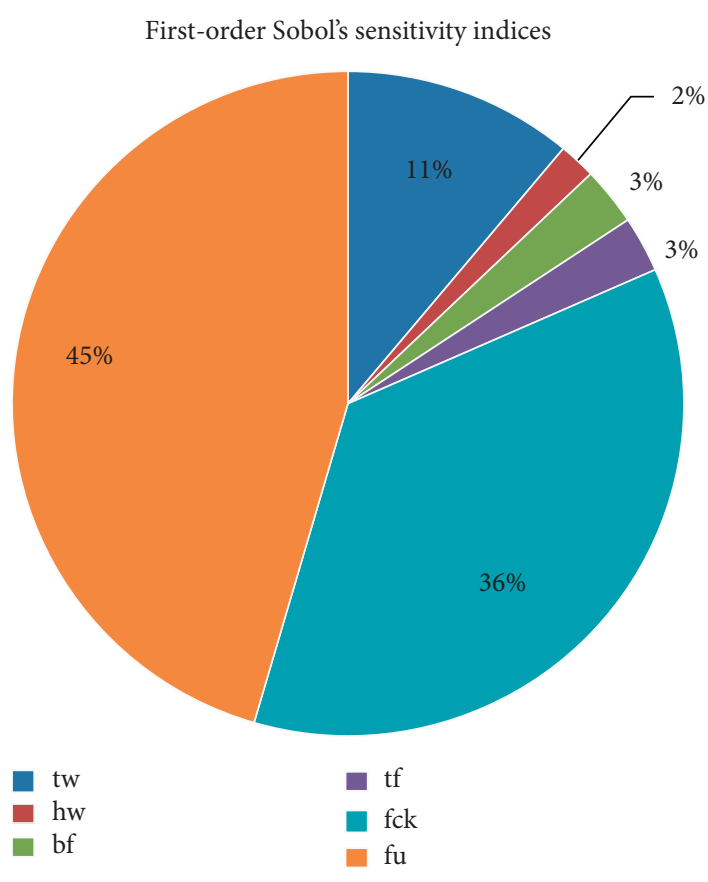

(a)

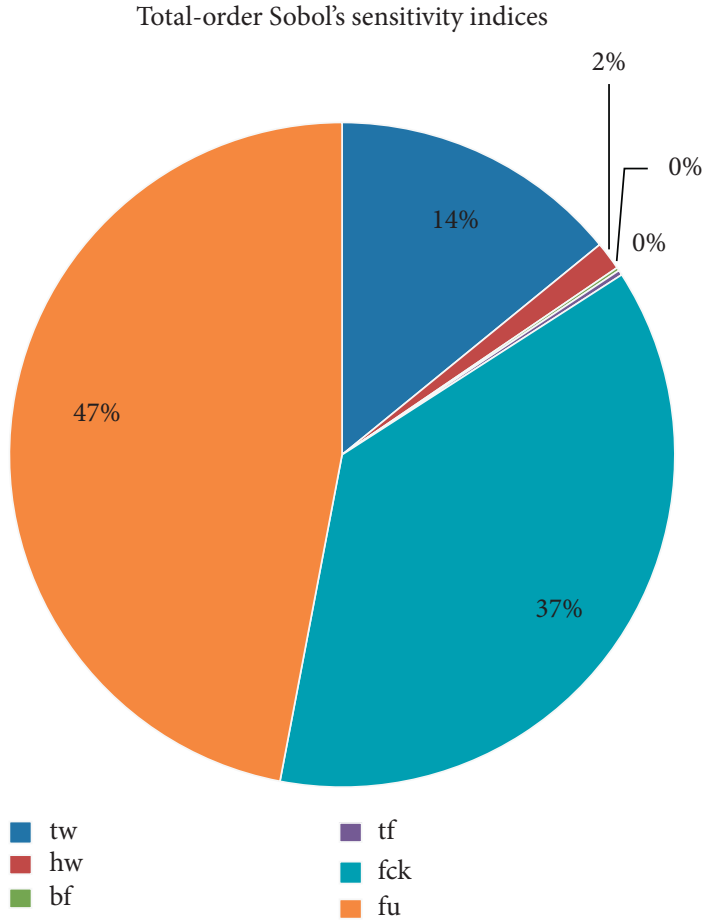

(b)

FIGURE 15: First-order and total Sobol's sensitivity indices of the 50-year corroded SCC beams.

and the total sensitivity indices, respectively, whereas $b_{f}$ and $t_{f}$ are the weakest input parameters for calculating the structural sensitivity with a proportion of mostly $0.0 \%$. Additionally, $h_{w}$ has a minor sensitivity index, implying an insignificant effect on the calculated reliability of the beam.

5.4. Structural Reliability and Sensitivity after 50-Year Corrosion. The reliability and sensitivity assessment of the SCC beams considering 50-year corrosion are performed in this section. The analysis method is similar to those which are presented in the previous sections. Figure 14 shows the convergence of the safe probability of the 50-year corroded SCC beams using Monte Carlo simulation. The probability of safety is converged at 0.8854 after 1800 samplings with 8minute computation. It can be seen that the safe probability value has a decrease of $9.61 \%$ compared to the pristine case. In other words, after 50-year corrosion, the reliability of the beam has decreased by $9.61 \%$. This reduction is significant and thus needs to be considered in the design process.
Table 10 and Figure 15 show the influence input random variables on the safe condition of the 50-year corroded SCC beams using Sobol's sensitivity indices. Again, the parameters, $f_{c k}$ and $f_{u}$ show to be the most important input random variables, with a proportion of $37.0 \%$ and $47.0 \%$ of the total sensitivity indices, respectively. In the case of the total sensitivity indices, $t_{f}$ has a moderate influence $(14.0 \%)$ on the total safe condition of the SCC beam. Additionally, $h_{w}$ has a minor sensitivity index (2\%), implying an insignificant effect on the calculated reliability of the beam.

Figure 16 shows the structural reliability of SCC beams with different service times. Again, it is emphasized that the reliability of the beam is decreased as service life increased. Figures 17 and 18 show the variation of the first-order and total sensitivity indices of the SCC beams with different corrosion levels ( 0 years, 10 years, 20 years, and 50 years). Again, it can be seen that the reliability of SCC beams is gradually reduced due to corrosion time. The effects of input parameters on the calculated reliability of the structure are significant. Therefore, it is important to consider the input 


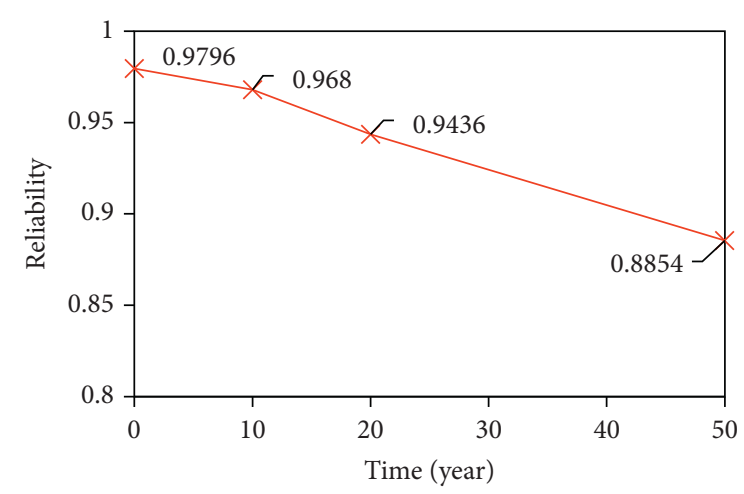

FIGURE 16: Variation of reliability of SCC beams with service time.

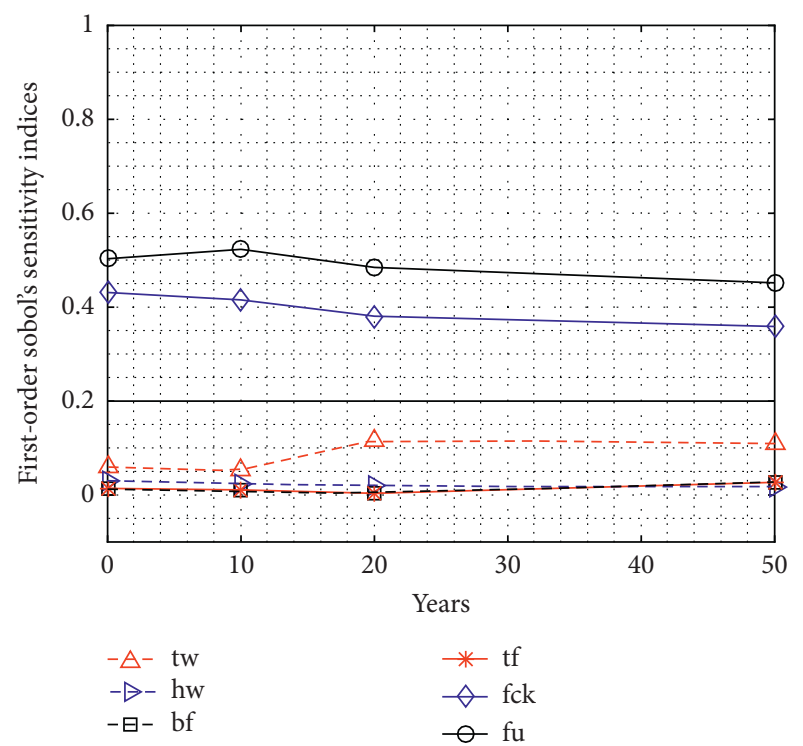

FIGURE 17: First-order Sobol's sensitivity indices of the SCC beams considering 0 -year, 10-year, 20-year, and 50-year corrosion levels.

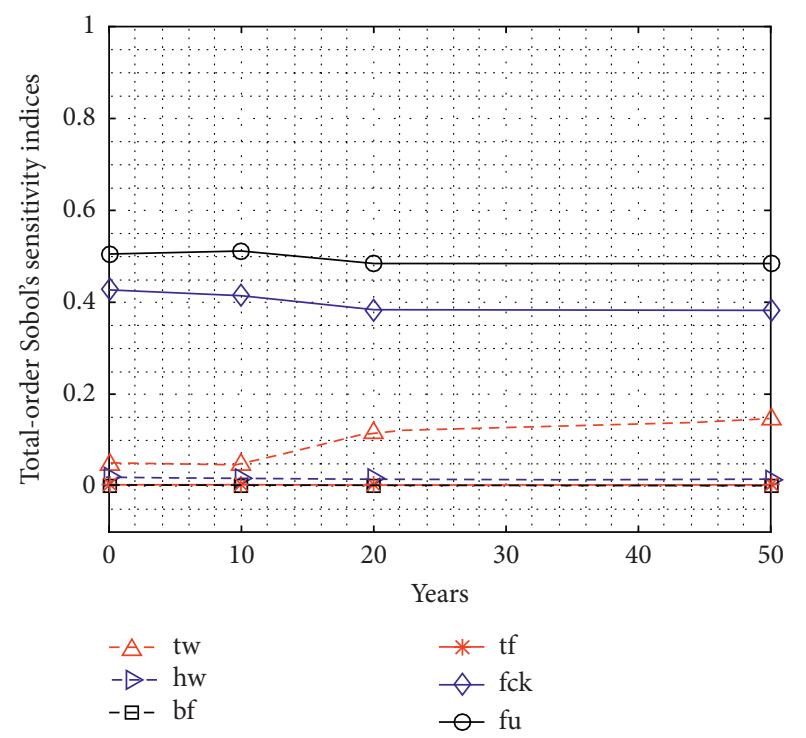

FIGURE 18: Total-order Sobol's sensitivity indices of the SCC beams considering 0 -year, 10-year, 20-year, and 50-year corrosion levels. random variables when adjusting the reliability of SCC beams at the design time.

\section{Conclusions}

This paper proposes an algorithm to assess the structural reliability and sensitivity of the steel-concrete composite (SCC) beam considering the influence of metal corrosion. The numerical calculations are developed based on Monte Carlo simulation, in which the uncertainty model is employed to account for the randomness of input variables. A wide range of corrosive exposing times, from 10 years to 50 years, is considered in the structural reliability and sensitivity assessment. The following conclusions are drawn based on numerical analyses:

(1) The proposed algorithm, which is capable of evaluating the structural reliability of corroded SCC beams, is developed based on Komp's corrosion model and Monte Carlo simulation.

(2) A variation of structural reliability with corrosively exposing time is quantified. Overall, the probability of safety of SCC beams is reduced by $9.61 \%$ as corrosion time increased to 50 years.

(3) An important recommendation for the selection of the input random variables is emphasized when adjusting the structural reliability of SCC beams in the design process.

(4) The developed procedure in this study can be extended to other structures such as SCC columns. However, additional numerical tests and verifications are required.

\section{Data Availability}

All the data supporting the key findings of this paper are presented in the figures and tables of the article. Requests for other data will be considered by the corresponding author.

\section{Conflicts of Interest}

The authors declare that they have no conflicts of interest.

\section{Acknowledgments}

This study was supported by project no. B2020-TDV-05 funded by the Ministry of Education and Training, Vietnam.

\section{References}

[1] G. H. Koch, M. P. Brongers, N. G. Thompson, Y. P. Virmani, and J. H. Payer, Corrosion cost and preventive strategies in the United States, Federal Highway Administration, Washington, DC, USA, 2002.

[2] R. Landolfo, L. Cascini, and F. Portioli, "Modeling of metal structure corrosion damage: a state of the art report," Sustainability, vol. 2, no. 7, pp. 2163-2175, 2010.

[3] D. M. Hamby, "A review of techniques for parameter sensitivity analysis of environmental models," Environmental Monitoring and Assessment, vol. 32, no. 2, pp. 135-154, 1994. 
[4] H. Yalciner, S. Sensoy, and O. Eren, "Effect of corrosion damage on the performance level of a 25-year-old reinforced concrete building," Shock and Vibration, vol. 19, no. 5, pp. 891-902, 2012.

[5] A. Petcherdchoo, "Probability-based sensitivity of service life of chloride-attacked concrete structures with multiple cover concrete repairs," Advances in Civil Engineering, vol. 2018, p. 17, 2018.

[6] M. S. Darmawan, R. Bayuaji, N. Husin, and R. Anugraha, "Case study of remaining service life assessment of a cooling water intake concrete structure in Indonesia," Advances in Civil Engineering, vol. 2014, p. 16, 2014.

[7] E. Romano, L. Cascini, M. D’Aniello, F. Portioli, and R. Landolfo, A simplified multi-performance approach to lifecycle assessment of steel structures, in Structures, pp. 371-382, Elsevier, Amsterdam, Netherlands, 2020.

[8] R. Landolfo, L. Cascini, and F. Portioli, "Sustainability of steel structures: towards an integrated approach to life-time engineering design," Frontiers of Architecture and Civil Engineering in China, vol. 5, no. 3, p. 304, 2011.

[9] L. Cascini, F. Portioli, and R. Landolfo, "Probabilistic time variant assessment of thin-walled steel members under atmospheric corrosion attack," Journal of Civil Engineering and Management, vol. 20, no. 3, pp. 404-414, 2014.

[10] G. Di Lorenzo and R. Landolfo, "Sensitivity study of dynamics variability for mild-carbon steel structures affected by corrosion," The Open Construction \& Building Technology Journal, vol. 13, no. 1, pp. 251-268, 2019.

[11] A. Der Kiureghian, "Structural reliability methods for seismic safety assessment: a review," Engineering Structures, vol. 18, no. 6, pp. 412-424, 1996.

[12] H. Hong and S. Wang, Reliability of Steel Frame Systems with Semi-rigid Connections, Institute for Catastrophic Loss Reduction, Toronto, ON M5C 2R9, Canada, 2003.

[13] M. A. Hadianfard and R. Razani, "Effects of semi-rigid behavior of connections in the reliability of steel frames," Structural Safety, vol. 25, no. 2, pp. 123-138, 2003.

[14] N. Kishi, W. Chen, Y. Goto, and K. Matsuoka, "Design aid of semi-rigid connections for frame analysis," Engineering Journal, vol. 30, no. 3, pp. 90-107, 1993.

[15] A. Kozlowski, R. Kowalczyk, and M. Gizejowski, "Estimation of the initial stiffness and moment resistance of steel and composite joints," in Proceedings of the CTBUH 8th World Congress, Dubai, UAE, March 2008.

[16] Z. Zhao, A. Haldar, and F. L. Breen Jr, "Fatigue-reliability evaluation of steel bridges," Journal of Structural Engineering, vol. 120, no. 5, pp. 1608-1623, 1994.

[17] T. V. Galambos, "Reliability of the member stability criteria in the 2005 AISC Specification," International Journal of Steel Structures, vol. 4, no. 4, pp. 223-230, 2004.

[18] A. Mamuda, I. Abubakar, and D. Samson, "Reliability-based structural safety evaluation of concrete-steel composite beams according to euro code 4," Engineering Physics, vol. 2, no. 2, p. 32, 2018.

[19] Y. Luo, A. Li, and Z. Kang, "Reliability-based design optimization of adhesive bonded steel-concrete composite beams with probabilistic and non-probabilistic uncertainties," Engineering Structures, vol. 33, no. 7, pp. 2110-2119, 2011.

[20] V. Piluso, G. Rizzano, and I. Tolone, "Seismic reliability assessment of a two-story steel-concrete composite frame designed according to Eurocode 8," Structural Safety, vol. 31, no. 5, pp. 383-395, 2009.
[21] Y. Luo, Z. Kang, and A. Li, "Structural reliability assessment based on probability and convex set mixed model," Computers \& Structures, vol. 87, no. 21-22, pp. 1408-1415, 2009.

[22] F. N. Leitão, J. G. S. Da Silva, P. C. G. Da S Vellasco, S. A. L. De Andrade, and L. R. O. De Lima, "Composite (steelconcrete) highway bridge fatigue assessment," Journal of Constructional Steel Research, vol. 67, no. 1, pp. 14-24, 2011.

[23] G. Fabbrocino, G. Manfredi, and E. Cosenza, "Modelling of continuous steel-concrete composite beams: computational aspects," Computers \& Structures, vol. 80, no. 27-30, pp. 2241-2251, 2002.

[24] R. E. Melchers, "The effect of corrosion on the structural reliability of steel offshore structures," Corrosion Science, vol. 47, no. 10, pp. 2391-2410, 2005.

[25] J. R. Kayser and A. S. Nowak, "Capacity loss due to corrosion in steel-girder bridges," Journal of Structural Engineering, vol. 115, no. 6, pp. 1525-1537, 1989.

[26] R. Landolfo, G. Di Lorenzo, and M. Guerrieri, "Modelling of the damage induced by atmospheric corrosion on 19th century iron structures," in Proceedings of the Italian National Conference on Corrosion and Protection, Senigallia, Italy, July 2005.

[27] A. A. Czarnecki and A. S. Nowak, "Time-variant reliability profiles for steel girder bridges," Structural Safety, vol. 30, no. 1, pp. 49-64, 2008.

[28] E. Fontaine, A. Potts, R. E. Melchers, A. Arredondo, and K.-t. Ma, "Investigation of severe corrosion of mooring chain in west african waters," in Proceedings of the The TwentySecond International Offshore and Polar Engineering Conference, Rhodes, Greece, June 2012.

[29] I. M. Sobol, "Global sensitivity indices for nonlinear mathematical models and their Monte Carlo estimates," Mathematics and Computers in Simulation, vol. 55, no. 1-3, pp. 271-280, 2001.

[30] J. Morio, "Global and local sensitivity analysis methods for a physical system," European Journal of Physics, vol. 32, no. 6, p. 1577, 2011.

[31] W. Qi, C. Zhang, J. Chu, and H. Zhou, Sobol's Sensitivity Analysis for TOPMODEL Hydrological Model: A Case Study for the Biliu River Basin, China, p. 1, Editorial Board, Beijing, China, 2013.

[32] I. M. Sobol, "Sensitivity estimates for nonlinear mathematical models," Mathematical Modelling and Computational Experiments, vol. 1, no. 4, pp. 407-414, 1993.

[33] A. Saltelli, "Making best use of model evaluations to compute sensitivity indices," Computer Physics Communications, vol. 145, no. 2, pp. 280-297, 2002.

[34] M. Lemaire, A. Chateauneuf, and J.-C. Mitteau, "Fiabilité des structures," European Journal of Computational Mechanics, vol. 15, no. 7, 2005.

[35] M. Komp, "Atmospheric corrosion ratings of weethering steels-calculation and significance," Materials Performance, vol. 26, no. 7, pp. 42-44, 1987.

[36] J. R. Kayser and A. S. Nowak, "Reliability of corroded steel girder bridges," Structural Safety, vol. 6, no. 1, pp. 53-63, 1989.

[37] M. Secer and E. T. Uzun, "Corrosion damage analysis of steel frames considering lateral torsional buckling," Procedia Engineering, vol. 171, pp. 1234-1241, 2017.

[38] S. H. BEng and S. Park, EN 1994-Eurocode 4: design of composite steel and concrete structures, Report of The Steel Construction Institute, Berkshire, UK, 1994.

[39] T. Ishigami and T. Homma, "An importance quantification technique in uncertainty analysis for computer models," Institute of Electrical and Electronics Engineers, in Proceedings 
of the [1990] First International Symposium on Uncertainty Modeling and Analysis, pp. 398-403, College Park, MD, USA, December 1990.

[40] P. Hoi, Composite Steel-Reinforced Concrete for High Building, Publishing of Scientific and Technical, Hanoi, Vietnam, 2010.

[41] F. M. Bartlett, R. J. Dexter, M. D. Graeser, J. J. Jelinek, B. J. Schmidt, and T. V. Galambos, "Updating standard shape material properties database for design and reliability," Engineering Journal-American Institute of Steel Construction Inc, vol. 40, no. 1, pp. 2-14, 2003.

[42] B. Ellingwood, J. G. MacGregor, T. V. Galambos, and C. A. Cornell, "Probability based load criteria: load factors and load combinations," Journal of the Structural Division, vol. 108 , no. 5, pp. 978-997, 1982. 